\title{
Marcos em relação ao desenvolvimento sustentável e o crescente nexo ambientalista inserido no fenômeno dos megaeventos esportivos
}

\author{
Elaine Gomes Borges da Silva* \\ EB Consultoria (Brasil) \\ Laila Borges da Silva** \\ Universidade Federal Fluminense (Brasil)
}

\begin{abstract}
Resumo: Esta pesquisa de caráter qualitativo tem como objetivo trazer à compreensão como foi incorporado o conceito de sustentabilidade à realização dos megaeventos esportivos. De método descritivo, foram apresentados marcos decisórios nesse processo histórico ao qual o nexo ambientalista foi seu principal norte. Para atingir tal proposta, foi realizada a pesquisa bibliográfica e a análise documental. Estas permitiram identificar os fatos correlatos à inserção da sustentabilidade aos megaeventos e identificar o significado do megaevento enquanto segmento e fenômeno complexo que o turismo engloba. A pesquisa na documentação de órgãos e entidades referentes ao tema proposto convergiu nas duas maiores organizadoras deste tipo de evento: o COI (Comitê Olímpico Internacional) e a FIFA (Federação Internacional de Futebol Associado). Este resultou nas considerações de uma dessas mencionadas, ao qual foi elencado o basilar documento Football Stadium: recomendation and requirements e o Green Goal, programa da FIFA - a organizadora da Copa do Mundo entre outros campeonatos de futebol - para possibilitar reflexões sobre desenvolvimento sustentável e o impacto dos eventos na localidade anfitriã.
\end{abstract}

Palavras-chave: Turismo; Sustentabilidade; Megaeventos esportivos, Ambientalismo, instalação esportiva, localidade anfitriã.

Landmarks in relation to sustainable development and the growing environmental emphasis in sport mega-events

Abstract: This qualitative research is directed at understanding how the concept of sustainability is incorporated into sport mega events. Using a descriptive method, decision-making frameworks are presented in this historical process where Nature and climate are the major guiding features together with a review of the existing literature. These allowed us to identify how sustainability works in mega-events and also to identify the significance of said events in the braoder context of tourism. The documents researched mainly converged on the two largest organizers of this type of event in our country: the International Olympic Committee (IOC) and FIFA (International Federation of Associated Football). This present article is limited to one major element, the sustainability of a Football Stadium: recommendations and requirements and Green Goal, the FIFA programme - the organizer of the World Cup among other soccer championships - to enable reflection on sustainable development and the impact of events on the host location.

Keywords: Tourism; Sustainability; Sporting mega events; Environmentalism, sports installation, host city.

\footnotetext{
Mestre em Turismo e especialista em Gestão de Negócios Turísticos pela Universidade de Brasília - UnB; E-mail: elaineborgesturismo@hotmail.com

** Graduanda do curso de Sociologia no IFCS - Instituto de Filosofia e Ciências Sociais da Universidade Federal Fluminense - UFF e do curso de Ciência Política da Universidade Autonôma de Manizales (Colômbia); E-mail: lailaborgess@gmail.com
} 


\section{Introdução}

Na década de 1980, os megaeventos esportivos surgiram como novo modelo de entretenimento para o público em geral, meio de divulgação do país sede no exterior e ampliação de divisas entre outros fatores não menos relevantes. Na mesma época aconteceram as discussões mundiais sobre o meio ambiente e a ecologia. Em 1987 foi instituído o conceito de sustentabilidade no relatório de Brundtland (United Nations, 1987), que tem como princípio a utilização dos recursos no presente idealizando sua manutenção e economia para a garantia de uso para gerações futuras.

Conjecturado que além do olhar economicista deveria ser preservado o meio ambiente e seus recursos naturais, agregar o capital humano e a qualidade de vida, os organizadores de eventos deveriam acompanhar este paradigma. Assim coube neste estudo como o ideário da sustentabilidade foi incorporado ao turismo e acabou absorvido pelas organizadoras dos grandes eventos esportivos internacionais. Para responder como elas anexaram a sustentabilidade aos seus negócios, o objetivo geral foi identificar marcos que fizeram por incorporar o nexo ambientalista a este segmento tão importante para o Turismo.

Para viabilizar este estudo, os objetivos específicos foram: revisar a bibliografia e a documentação de órgãos e entidades referentes ao tema proposto e identificar o significado do megaevento enquanto segmento e fenômeno complexo que o turismo engloba. Na segunda etapa foram ordenadas as informações obtidas pela data dos acontecimentos e resoluções em ordem crescente e identificado um modelo de planejamento de sustentabilidade para o evento de uma dessas organizadoras.

A pesquisa convergiu ao encontro das duas maiores organizadoras deste tipo de evento da atualidade: o Comitê Olímpico Internacional - COI e a Federação Nacional de Futebol Associado - FIFA, sendo esta última elencada para possibilitar análises e reflexões acerca das condições ideais para uma instalação esportiva e para a localidade sede de megaevento. Além de introdução, método e considerações finais, o artigo está disposto no arcabouço com os subtítulos: O Fenômeno Megaevento na Complexidade que o Turismo de Eventos engloba; A Influência dos Megaeventos Esportivos na Infraestrutura das Cidades Anfitriãs; Processos Decisórios na Inserção da Sustentabilidade aos Megaeventos Esportivos; e, As Considerações da Entidade FIFA em relação à Instalação Esportiva e a Localidade Anfitriã.

O estudo se fez relevante pelo ineditismo do Brasil, país que tem expertise em construções sustentáveis - o quarto colocado no ranking de edificações sustentáveis - ser o pioneiro na América Latina em sediar o megaevento esportivo Jogos Olímpicos 2016, ter sediado duas edições dos Jogos Pan Americanos (1963 e 2007) e também da Copa do Mundo de Futebol (1950 e 2014). Exceto o Pan Americano na cidade de São Paulo, todos os demais utilizaram o estádio Mário Filho, a instalação esportiva do Maracanã na cidade do Rio de Janeiro/BR. A Estratégia de Sustentabilidade aplicada ao estádio do Maracanã e aos demais na Copa do Mundo 2014 conforme aponta a FIFA (2011) será paradigma para futuros eventos internacionais. Acredita-se que a compreensão de como foi incorporado o conceito de sustentabilidade para os eventos deve ser difundido tanto na comunidade acadêmica envolvida no estudo do turismo de eventos quanto na sociedade civil, devido às implicações que a realização de megaeventos pode ocasionar para os autóctones das cidades anfitriãs a que alguns autores citam como stakeholders, considerando diferentes categorias.

Mitchell et al (1997) estabelecem uma classificação de stakeholders com base nos atributos: poder, legitimidade e urgência. Para estes autores eles podem ser visíveis ou latentes, e podem se manifestar a qualquer momento. Podem ser considerados stakeholders: os acionistas, os fornecedores, os empregados, os administradores, a comunidade e os consumidores. (Freeman, 2010); funcionários, governo, mídia e Organizações Não Governamentais - ONG's (Oliveira, 2008), os sindicatos e os concorrentes (Sousa e Almeida, 2006). Aqui se justifica a sociedade civil na categoria de stakeholder, são os autóctones envolvidos pelas implicações que os megaeventos podem causar, pelos impactos ao ambiente da localidade receptora, alterando a rotina da comunidade e com outras externalidades que afetam esses atores sociais.

\subsection{Metodologia}

De método descritivo, este artigo tomou o cunho da pesquisa qualitativa. Conforme Duarte (2002), nesse tipo de pesquisa cabe produzir interpretações e explicações que procurem dar conta do problema e das questões que motivaram a investigação. As muitas leituras do material de que se dispõe, cruzando informações aparentemente desconexas, interpretando respostas, notas e textos integrais que são codificados no que o autor denomina de caixas simbólicas, categorias teóricas ou categorias nativas ajudam a classificar com certo grau de objetividade o que se depreende da leitura daqueles diferentes textos.

Para a construção metodológica foi pesquisado Morin (2003; 2011). Conforme este autor, a educação dominante troca o todo pela parte, separa os objetos do seu contexto, fragmentando o mundo, fracionando 
os problemas e impedindo as pessoas que compreendam melhor a realidade. Para Morin $(2003 ; 2011)$ a produção do conhecimento e da elucidação de problemas deve ser realizada pelo todo, sem reducionismos - o indivíduo deve olhar de maneira totalizante. Um pensamento não fragmentado que permite que o homem, ao analisar a vida e o mundo, perceba tudo que está à sua volta para que ele construa um entendimento mais abrangente a respeito dos problemas da humanidade em um contexto planetário (Morin, 2003). Assim para compreender os marcos decisórios que chegaram ao que se verificou atualmente nos megaeventos esportivos no quesito desenvolvimento sustentável, a autora do estudo observou ser necessário buscar o olhar da pesquisa às reflexões do estudo do Turismo enquanto ciência e fenômeno para compreender a atividade turística que insere o segmento de eventos.

$\mathrm{O}$ artigo englobou uma pesquisa bibliográfica da literatura acadêmica relacionada ao turismo, aos eventos e a sustentabilidade. Assim viabilizou-se uma revisão bibliográfica que esclareceu sobre os significados de eventos sustentáveis, megaeventos e megaeventos esportivos, instalações esportivas necessárias para a realização dessa tipologia de eventos e suas influências para o turismo, para a comunidade e as cidades, que deram suporte ao arcabouço do artigo. E a pesquisa documental indicou que o artigo deveria ser recortado para análise no documento da FIFA, o Footbal Stadium: recomendation and requirements. Neste estudo o foco principal era a busca pelo que iniciou o pensar do desenvolvimento sustentável na tipologia desses eventos de porte macro.

O quadro interpretativo escolhido foi o método dialético, por permitir interpretação dinâmica e totalizante da realidade uma vez que tudo se relaciona num contexto social, político e econômico.

\section{2. $\mathrm{O}$ fenômeno megaevento na complexidade que o turismo de eventos engloba}

Megaeventos têm o mesmo significado dos macroeventos que são, como conceitua Campos et al (2000), aqueles que permitem a ocupação de todo o parque hoteleiro de uma ou várias cidades, mobilizam milhares de pessoas nos processos de organização e operação e têm participação do setor público na esfera - federal, estadual ou municipal. A coordenação geralmente é estabelecida para ficar a encargo de entidade pública que costuma lançar mão da contratação de terceiros para atuar em diversas áreas, inclusive com a participação do setor privado por meio de parcerias; a divulgação se dá a nível internacional; costuma atrair e envolver diversos atores, mobilizando toda a região da sede; e geralmente, para sua promoção as empresas escolhidas são as maiores do mercado nacional e internacional.

Megaeventos são acontecimentos raros, únicos, de duração limitada e de atenção em massa. Em termos das dimensões físicas ou financeiras, podem atrair atenção por meio de propaganda paga ou da publicidade gratuita devido ao crescente interesse midiático (Nielsen, 2002). À medida que a data do evento se aproxima as coberturas midiáticas vão ganhando grandiosidade (Gastaldo, 2002) e essas ações servem para o aumento da consciência, atração e lucratividade de um destino turístico a curto ou longo prazo cujo sucesso depende de sua originalidade, status ou significado favorável para criar interesse e atrair atenção (Ritchie e Yangzhou, 1987), "sua magnitude afeta economias inteiras e repercute na mídia global" (Getz, 1997, p. 6).

O número de visitantes em um megaevento pode chegar a um milhão de pessoas, tem orçamento de pelo menos US\$ 500 milhões, é voltado para o mercado turístico internacional e pode ser caracterizado pela grandiosidade ou significado no que compreende ao público e mercado-alvo, grau de envolvimento financeiro do setor público, construção de instalações e pelos efeitos políticos, no sistema econômico e social da comunidade anfitriã e a extensão de cobertura televisiva (Allen et al, 2008).

Campos et al (2000) denomina como macro evento essa tipologia que por sua dimensão, data e período fixo de quatro em quatro anos, perfil dos participantes também são chamados de megaeventos. Com a mesma formatação têm-se os Jogos Olímpicos, a Copa do Mundo e os Jogos Pan-Americanos. Raros e um pouco mais recentes na história, Mascarenhas et al (2011) apontam que fazem poucas décadas que os eventos esportivos internacionais ganharam a conotação de mega.

De acordo com Proni et al (2016) os impactos provocados por um megaevento esportivo podem ser classificados por diferentes critérios: positivos ou negativos, passageiros ou duradouros, tangíveis ou intangíveis, locais ou nacionais. Também podem ser diferenciados de acordo com o campo de interesse: econômico, político, social, ambiental e esportivo. Segundo este autor os impactos de natureza econômica (diretos ou indiretos) são os que despertam maiores esforços de mensuração. Os impactos diretos são os associados imediatamente à preparação e realização do torneio (estímulo a segmentos econômicos, contratação de trabalhadores, movimento e gasto médio de turistas, composição do gasto público etc.), enquanto os indiretos são os seus desdobramentos na economia causados pelo gasto adicional das 
empresas que foram diretamente estimuladas e pelo consumo dos trabalhadores que foram contratados em função do megaevento (esses impactos são estimados com base numa matriz de insumo-produto).

Desde a candidatura e a conquista do direito de sediar o megaevento até a véspera de sua realização, o governo e demais grupos de interesse tentam demonstrar, por meio de estudos ex ante, os benefícios que podem resultar para toda a população, como o aumento do número de empregos, a expansão das oportunidades de negócio, o incremento no turismo, o crescimento do PIB, entre outros. A intenção desses grupos é legitimar as medidas tomadas nas cidades sede e justificar os gastos do uso de fundos públicos na construção ou reforma de instalações esportivas assim como no atendimento das exigências impostas pelos responsáveis pelo megaevento. (OWEN, 2005).

Em Del Río Rama et al (2016) está que, conforme explicam Shipway e Fyall (2012) eventos esportivos podem gerar benefícios nos campos do esporte por meio de maior participação; impactar nos aspectos sociais no caso da comunidade anfitriã, incluindo a regeneração social, o orgulho nacional e regional ou o aumento do trabalho voluntário; gerar benefícios econômicos em termos de emprego, investimentos nacionais ou investimentos em infra-estrutura; apoiar iniciativas ambientais através de instalações sustentáveis, acessíveis; e, finalmente, proporcionar oportunidades para a melhoria do turismo, incluindo o aumento de padrões de serviço, substituição de destino e a criação de uma marca.

\section{A influência dos megaeventos na infraestrutura da cidade e no turismo}

Os megaeventos esportivos costumam reunir diversas outras tipologias de eventos no arcabouço de seu projeto (Dacosta et al, 2008). Assim, uma gama de eventos estará integrada ao evento principal (Britto e Fontes, 2002). De acordo com a importância e a abrangência do evento, os critérios de avaliação são proporcionalmente rigorosos: elevação do nível de geração de emprego; incremento no número das vagas de trabalho temporário; maior produtividade no trade turístico (o segmento que recebe maior impacto com a captação de eventos). De porte; prestígio internacional para a entidade, investidores e coordenadores; e elevação da arrecadação de impostos, é lucrativa fonte de arrecadação devido ao gasto per capita mais elevado do que o turismo de lazer (Martin, 2003). De acordo com Del Río Rama et al (2016), as partes interessadas e beneficiárias dos megaeventos dividem-se em três grupos. São elas as administrações políticas locais, as empresas locais e, não menos importante nessa rede, a população local.

Megaeventos esportivos trazem novas instalações específicas para o desporto em suas cidades sede, custos com a manutenção física e do quadro de colaboradores na ordem de $10 \%$ do seu valor, que se justificam na utilização para o município por meio de algum programa de prática esportiva, aluguel do espaço ou parcerias para dar uma nova utilização à instalação (Dacosta et al, 2008). Para Bonnenfant (2001) é fácil compreender que os encargos gerados por essas instalações produzam ônus, havendo grande risco de deterioração daquele patrimônio se a manutenção não for apropriada e permanentemente assegurada. Conforme Preuss (2000), as estruturas primárias e algumas secundárias são frequentemente construídas especificamente para o megaevento programado, enquanto que estrutura terciária contempla as já existentes ou previstas no plano diretor urbano da cidade independente da realização do megaevento, tendo seu desenvolvimento apenas antecipado ou acelerado.

Às cidades dos megaeventos ainda requerem organizar instalações potencialmente disponíveis. Considerando que infra-estruturas primárias e algumas secundárias frequentemente são construídas de maneira específica, o legado deve ser planejado na estruturação destas instalações para os jogos. As instalações esportivas primárias/permanentes, devem receber um planejamento inteligente a partir da análise das necessidades da comunidade, objetivando pós evento determinar os possíveis programas a serem implementados no conjunto das instalações esportivas (Preuss, 2005) (Vigneau, 1998). A instalação esportiva pode ser do tipo permanente ou temporário e cabe aos planejadores e projetistas não perder o foco que será um legado tão mais positivo quanto maior for a capacidade em atender alternativas de pós-uso, além daquelas de alto rendimento para as quais foram basicamente construídas. Estudos prévios na construção dessas instalações farão com que os planejadores fiquem atentos à demanda da população local, dando assim um sentido aos custos acarretados. (Ribeiro, 2008).

As instalações inerentes aos megaeventos esportivos podem ser do tipo estádio, a princípio construídos para esporte único; arena - espaço para esportes, cultura, entretenimento, convenções ou feiras de negócios. Em geral, já existentes em cidades que sediam grandes eventos ou eventos em larga escala; pavilhão (inicialmente era o pavilhão de exposições, originado no séc. XIX no âmbito das grandes exposições e feiras industriais, atualmente de uso alternativo é o pavilhão de feiras de negócios e centros de convenções que frequentemente são convertidos de modo temporário em instalações esportivas; 
pequenos estádios e ginásios, em geral são instalações desprovidas de grande arquibancada, funcionando para o treinamento das delegações; velódromos e piscinas: instalações especiais, os velódromos podem ser montados para serem instalações temporárias devido ao seu uso limitado. Já as piscinas servem a algumas modalidades de esportes aquáticos e têm ainda as instalações de uso padrão, que são os clubes esportivos, as piscinas públicas, as quadras de escolas entre outros (Preuss, 2000).

Conforme Preuss (2000) harmonizar ou compatibilizar as estruturas necessárias para os megaeventos com a construção de uma instalação economicamente sustentável após os jogos é algo muito difícil. A instalação deve ser suficientemente flexível para que, por meio de eventos culturais, políticos, religiosos se possam cobrir seus custos de manutenção.

Atualmente, pós evento, há tendência em transformar as instalações esportivas em atrações por meio do estímulo ao turismo, ao comércio, às atividades cívicas e a realização de tour arquitetônico pelos estádios (Dacosta et al, 2008). Como exemplo vide o caso do estádio do Maracanã na cidade do Rio de Janeiro e o seu tour oferecido pós a Copa do Mundo de 2014 (Silva, 2015). Nos estádios há maior valorização dos espectadores porque os eventos esportivos são fontes primárias do inesperado e do imprevisível. Os estádios ganham importância como novos ícones, demandando mais que competência técnica para sua construção que daqueles especialistas de outrora. (Ribeiro, 2008). Standeven e De Knop (1999) apontam para a possibilidade de encontrar exemplos de turismo que gera valor permanente ao esporte na comunidade local em instalações construídas com um objetivo turístico, mas que possuem desmembramentos que ultrapassam sua função inicial. Instalações construídas de acordo com padrões internacionais geralmente são sofisticadas demais para o uso da comunidade (Nielsen, 2002).

Os projetos das cidades postulantes referem sempre em proposta de que estas instalações ficarão de legado para a comunidade do entorno da instalação. Porém a sofisticação dada a estas instalações costuma significar alta nos preços dos ingressos e o requinte técnico dos equipamentos os torna mais interessantes como locais de comercialização que espaço de práticas sociais ou comunitárias da população autóctone.

\section{Processos decisórios na inserção da sustentabilidade aos megaeventos}

A partir da década de 1980, num contexto de escassez de transferência de recursos com cortes dos investimentos do governo central americano, mudanças na política urbana e no acirramento da competição global, iniciou o interesse dos políticos de administrações locais pelos megaeventos para nortear a gestão do seu território de modo empreendedor. Observou-se que os megaeventos poderiam ser utilizados como estratégia de diferenciação para atrair investimentos para o núcleo urbano oportunizando novo cenário de desenvolvimento (Andranovich et al, 2001).

O termo sustentabilidade popularizou-se a partir de 1986 por meio da World Comission on Enviroment and Development (Comissão Mundial de Desenvolvimento Ambiental), cuja ideia era que a saúde do planeta dependeria da busca de meios que atendessem as necessidades do presente sem o comprometimento das necessidades das gerações futuras (Ribeiro, 2008). No Relatório Brundtland (1987) foi criado o conceito de Sustentabilidade e se destacam a proteção ambiental, o crescimento econômico e a equidade social que para muitos autores estes são os três componentes fundamentais para o desenvolvimento sustentável. Os três itens se complementam de modo inter-relacionado. (Elkington, 1999); (Ciegis et al, 2009).

Na década de 1990, refletindo as discussões mundiais que culminaram no conceito de sustentabilidade de 1987, surgiram as primeiras tentativas de aplicar esse novo paradigma aos megaeventos esportivos. (Mascarenhas et al., 2011). Iniciou também nessa mesma época uma maior preocupação com o meio ambiente diretamente relacionado à regeneração urbana. (Leme, 2008).

Na Conferência Mundial de Turismo Sustentável, realizada pela Organização Mundial do Turismo - OMT em 1990 (OMT, 1996) foram elencados os benefícios desta atividade: assegurar uma distribuição justa dos benefícios e custos; gerar empregos locais, diretos e indiretos; gerar entrada de divisas para o país, injetar capital na economia local; estimular o desenvolvimento do transporte local, comunicações e outras infraestruturas para a comunidade; estimular indústrias domésticas lucrativas; estimular a compreensão dos impactos do turismo; diversificar a economia local, sobretudo em áreas rurais onde o emprego agrícola pode ser esporádico ou insuficiente; procurar ser participativo na tomada de decisões entre os atores, e incorporar o planejamento e o zoneamento assegurando o desenvolvimento do turismo adequado à capacidade de carga do ecossistema; criar facilidades de recreação que podem ser usadas pela comunidade local; intensificar a autoestima da comunidade local através do turismo cultural; o fato de que demonstrar a importância dos recursos naturais e culturais para a economia de uma comunidade 
e seu bem-estar social pode ajudar a preservá-los; monitorar e administrar os impactos do turismo e opor-se a qualquer efeito negativo (Swarbrooke, 2001).

Em 1992, a Conferência Mundial do Meio ambiente e Desenvolvimento - Cnumad da Organização das Nações Unidas - ONU, realizada no Rio de Janeiro com a presença de chefes de Estado de mais de 170 países, resultou em cinco documentos que servem de base para as negociações que envolvem o meio ambiente até os dias atuais (Senado Federal, 2012). Tem-se a Agenda 21, um instrumento de planejamento para a construção de sociedades sustentáveis em diferentes bases geográficas, que concilia métodos de proteção ambiental, justiça social e eficiência econômica (MMA, 2014). Assim, o conceito de turismo começou a ser alinhado a questão do desenvolvimento sustentável (Bartholo et al, 2005). Vale lembrar que na atividade turística se promove e vende destinos e produtos, ou seja, a cidade e os espaços construídos voltados a atender uma demanda turística.

Destacam-se a Agenda 21 voltada à Indústria da Viagem e Turismo ao Desenvolvimento do Turismo Sustentável (OMT, 1994), que delineou diretrizes para os departamentos de governo e organizações comerciais, apontando oito áreas de ação prioritárias para aqueles departamentos, as autoridades de turismo nacional, as organizações comerciais representativas e também empresas, são elas: (Irving, 1998)

- Avaliação da capacidade de quadro regulatório, econômico e voluntário para viabilização do turismo sustentável no sentido de apoiar o desenvolvimento de políticas que facilitem o alcance das metas desejadas;

- Avaliação das implicações econômicas, sociais, culturais e ambientais das operações da organização/ instituição, no sentido de examinar sua própria capacidade para atuar na direção da perspectiva de Desenvolvimento Sustentável;

- Treinamento, educação e consciência pública, no sentido do desenvolvimento de formas mais sustentáveis de turismo e com o objetivo de viabilizar a capacidade necessária para a execução de tarefas nesta direção;

- Planejamento para o desenvolvimento do turismo sustentável, a partir do desenvolvimento e implementação de medidas que assegurem o efetivo planejamento do uso do solo e mecanismos que maximizem benefícios ambientais e sociais e minimizem potenciais danos culturais ou ambientais;

- Facilitação de intercâmbio de informações, habilidades e tecnologias relativas ao turismo sustentável entre países desenvolvidos e países em desenvolvimento;

- Fomento ao envolvimento da participação de todos os setores da sociedade, incluindo as minorias;

- Monitoramento permanente de progresso para alcançar metas de desenvolvimento sustentável, a partir de indicadores realistas de turismo sustentável aplicáveis a nível local e nacional;

- Desenvolvimento de parceiras para a facilitação de iniciativas responsáveis.

No plano internacional, em 1992 o momento era propício para que as lideranças mundiais avançassem na agenda em prol do meio ambiente, com perspectivas de crescimento na economia depois da queda do Muro de Berlim e do bloco socialista no Leste Europeu (Senado Federal, 2012). Embora algumas cidades sede já apresentassem melhoras ambientais intencionalmente projetadas em consequência da própria regeneração urbana, como Tóquio, 1964, Seul, 1988 e os Jogos Olímpicos de Inverno (Leme, 2008), as Olimpíadas de Barcelona 92, na Espanha, que foi o primeiro megaevento esportivo a seguir uma nova tendência - o paradigma de planejamento de legado. (Mascarenhas et al., 2011).

A partir do ano de 1994 a questão ambiental passou a ser uma das prioridades do Comitê Olímpico Internacional - COI, o organizador dos Jogos Olímpicos, quando em Paris foi realizado o Congresso Olímpico junto à comemoração pelo centenário das Olimpíadas. Neste evento ficou estabelecido que o meio ambiente fosse, após o esporte e a cultura, o terceiro quesito em importância do movimento, apontando que a realização dos jogos deveria visar o estímulo à conscientização sobre o ambiente e o desenvolvimento sustentável (Trigueiro, 2003), reforçou formalmente seu posicionamento a favor da responsabilidade ambiental, sobretudo refletindo as decisões da Conferência da ONU. Em 1995, a carta olímpica foi emendada para inclusão do nexo ambientalista. (Leme, 2008)

Em 1997, foi criada a Declaração Ostersund do Turismo de Megaeventos na I Conferência Acadêmica do Estudo de Megaeventos. Esta recomenda que as pesquisas devem ser direcionadas para melhor compreender quesitos relativos àquele documento, foram eles: os efeitos desse segmento na criação da imagem dos países, regiões e turismo local; efeitos de curto e longo prazo relacionados a atração de visitantes e as consequências sociais e econômicas por ele originadas; a importância desses para realização de metas econômicas e sociais essenciais; o desenvolvimento de estratégias para a estruturação geral da política de planejamento turístico local, regional e nacional, as abordagens para otimizar os 
impactos turísticos de megaeventos e ainda a recomendação que estes sejam analisados em função dos efeitos sociais, econômicos, ambientais, culturais e físicos, para que haja um aperfeiçoamento na coordenação global da administração e pesquisa dos megaeventos, nos padrões e na metodologia que possibilitem comparações globais consistentes entre os eventos e maior cooperação entre governos, universidades e setores especializados para auxiliar o desenvolvimento social e econômico originado pelos megaeventos (Nielsen, 2002).

As Olímpiadas de Sidney 2000, na Austrália, foi o primeiro concebido com a tentativa de realizar um evento sustentável de porte macro, seguiu as orientações do COI priorizando a consciência ambiental e o desenvolvimento sustentável, previa ações como o controle do impacto de suas instalações, investimentos em novas linhas de transporte ferroviário, mínimo uso de materiais descartáveis e redução do uso de papel. (Mascarenhas et al., 2011). Recebeu a marca de Green Games (Jogos Verdes), buscou a colaboração de saberes e análises de organizações não governamentais ambientalistas como o Greenpeace. Eles foram o primeiro megaevento esportivo examinado por aquela organização que emitiu um relatório detalhado e razoavelmente positivo sobre o evento esportivo internacional. (Leme, 2008).

Desde o ano de 2008, o fato de principalmente os países desenvolvidos passarem por uma crise econômica que trouxe altos níveis de desemprego e insatisfação da população em relação aos seus líderes - até o ano de 2012 na Europa, 11 chefes de governo já haviam sido substituídos - fez com que muitas negociações sobre o meio ambiente emperrassem desde a conferência Rio 92. (Senado Federal, 2012)

Em 2009, a Assembleia Geral da ONU decidiu realizar uma conferência para celebrar o $20^{\circ}$ aniversário da Cnumad - a Rio 92 ou Cúpula da Terra - no ano de 2012 na cidade do Rio de Janeiro/RJ. Dois itens da agenda da Rio+20 foram "A Economia Verde no Contexto do Desenvolvimento Sustentável e da Erradicação da Pobreza" e "Estrutura Internacional para o Desenvolvimento Sustentável” (UNEP, 2011). Assim foi realizada de 13 a 22 de junho de 2012, a Conferência das Nações Unidas sobre Desenvolvimento Sustentável - Cnuds com a missão de renovar compromissos com o desenvolvimento sustentável em meio a urgências ambientais, sociais, econômicas e políticas que entravavam a definição de metas para evitar degradação do meio ambiente (Senado Federal, 2012).

De acordo com Silberberg e MC Dowel (2010), na escolha de materiais, produtos e serviços que norteiam os aspectos socioambientais devem ser considerados os princípios dos "quatro R" - repensar, reduzir, reutilizar, reciclar. Desde o planejamento este deve ditar todas as escolhas na busca de uma gestão socioambiental: repensar processos, produtos e tecnologias; reduzir o uso de materiais e recursos naturais; reutilizar o máximo possível e reciclar os materiais não reutilizados; analisar o ciclo de vida de um material antes de optar por usá-lo no evento; analisar a origem dos produtos e mitigar os excessos no consumo de água e energia.

Pela garantia da sustentabilidade na realização de eventos hoje em dia são consideradas abordagens na esfera da ecologia, da economia, do social, da cultura e da política que podem ser reaplicadas a depender de fatores como o tempo, o lugar, as pessoas e os recursos disponíveis. Desse modo, existiriam apenas caminhos possíveis para a prática da sustentabilidade nos eventos e não fórmulas prontas (Fontes et $a l$, 2008). A gestão ambiental e a responsabilidade social devem permear todo o processo sensibilizando e informando a todos, com o objetivo de divulgar a importância em preocupar-se com as questões da sustentabilidade, em construção conjunta para a superação de dificuldades (Silberberg e Mc Dowel, 2010).

\section{Análises sobre as considerações da entidade fifa em relação a instalação esportiva e a localidade anfitriã}

De acordo com FIFA (2011), a Copa do Mundo requer um estádio cujo local e ambiente aceitem muitos outros usos além dos exigidos durante a temporada normal de jogos. Têm melhor chance de serem escolhidos para sede de megaevento esportivo os locais com capacidade de expansão para atender as necessidades das funções adicionais como vilas de hospedagem dos atletas, instalações para a mídia, unidades de transmissão, centros de voluntários, centros de credenciamento e inúmeras áreas de estacionamento.

O Football Stadiums - technical recommendations and requirements é o documento que guia as intervenções na instalação esportiva. Este documento FIFA (2007) é basilar para as decisões pré construção, segurança, orientação e estacionamento, campo, jogadores e partidas oficiais, espectadores, hospitalidade, mídia, fornecimento de luz e energia, comunicações e as áreas adicionais. Para a Copa 2014 foi lançada sua versão em português, a $5^{\text {a }}$ edição, em FIFA (2011). 
Neste consta o conceito de sustentabilidade para a FIFA que está explicitado na dimensão ambiental através do Programa Green Goal - Gol Verde. O programa norteia como os gestores das cidades sede por meio dos seus comitês organizadores locais devem preparar a arena para as competições e cerimônias. Sobre a compatibilidade ambiental do local do estádio, a FIFA (2011) registra que é uma consideração de suma importância a seleção do local para realizar o evento, complexa e com grande peso político, a localidade deve ser cuidadosamente analisada. Como exemplo é citado que a maioria dos residentes ficaria bastante preocupada com a possibilidade de ter suas casas sombreadas por um novo e grande estádio. A proximidade com áreas residenciais é questão delicada e deverá ser evitada no desenvolvimento de um novo estádio. Entre outras, as preocupações ambientais usuais na elaboração de um novo estádio incluem: o aumento do tráfego de veículos; a grande quantidade de torcedores/pedestres barulhentos e frequentemente agressivos; o ruído dos eventos; a forte iluminação da edificação e dos eventos; o sombreamento nas propriedades adjacentes; e, a falta de atividade nos arredores do estádio nos períodos em que eventos não estão programados.

As principais metas do programa são relativas à água, à energia, aos rejeitos, ao transporte, à certificação indicadora de sustentabilidade e à pegada de carbono. Observa-se como exemplo que, para adentrar o estádio o público participante precisará ter mobilidade e acesso garantido. Assim o documento prevê ainda abrangências para o entorno do estádio. A respeito do uso da água o requerimento é prezar pela redução, pelo uso mais responsável da água potável, avaliar seu uso para os fins de irrigação, o armazenamento da água pluvial, a reutilização da água fluvial e da água das torneiras reaproveitando nos banheiros do estádio. No documento é defendido que um maior potencial econômico pode ser atingido através da instalação de tecnologia de economia de água em instalações sanitárias durante a fase de construção. (FIFA, 2011)

Conforme o documento, a emissão e a remoção de resíduos representam um elevado custo administrativo de um estádio. Deste modo é orientado evitar, reduzir e limitar a quantidade de rejeitos gerados por meio da reutilização de recipientes de bebidas, reciclando-os através de coleta seletiva e também pela introdução de alimentos e produtos promocionais sem embalagens. (FIFA, 2011). No quesito energia, o projeto de construção de estádios deve empregar atividades de baixo consumo de energia com a criação de sistemas de abastecimento mais eficientes. As áreas com potencial de economia de energia incluem o uso de tecnologia fotovoltaica. (FIFA, 2011)

Outro aspecto é a obtenção de certificação na categoria de construção sustentável. (FIFA, 2011). Alegando que a agenda de meio ambiente e sustentabilidade tem se desenvolvido intensamente em todo o mundo, o surgimento de vários métodos e sistemas de certificação tem facilitado o processo de definição de objetivos e a avaliação de impactos. A Certificação selecionada como indicadora de sustentabilidade dos estádios do megaevento esportivo foi a Leadership in Energy Efficient Design - LEED, Método de Avaliação da Sustentabilidade de Edifícios (Building Research Establishment Environmental Assessment Method - BREEAM), seu selo desenvolvido em 2002 pelo US Green Building Council - USGBC (Conselho de Construção Sustentável dos Estados Unidos) é considerado o principal selo para edificações no mundo - utilizado em 143 países - objetiva incentivar a transformação dos projetos, obra e operação das edificações, com foco na sustentabilidade de suas atuações. O nível do selo pode variar nas escalas de pontos: Certificado (40-49), Prata (50-59), Ouro (60-79) e Platina (80 - 110). (US Green Building Council, 2014)

No Football Stadiums - technical recommendations and requirements está descrito que os benefícios da certificação LEED abrangem o valor econômico com a diminuição dos custos operacionais; a diminuição dos riscos regulatórios; a valorização do imóvel para revenda ou arrendamento; o aumento na ocupação; o aumento da retenção; modernização e menor obsolescência da edificação; pelo valor social na melhora da segurança e na priorização da saúde dos trabalhadores e ocupantes da arena; pela inclusão social e o aumento do senso de comunidade; capacitação profissional; conscientização de trabalhadores e usuários; o aumento da produtividade dos funcionários; a melhora na recuperação de pacientes em hospitais e no desempenho dos alunos nas escolas; no comércio, há o aumento no ímpeto de compra dos consumidores; o incentivo aos fornecedores com maiores responsabilidades socioambientais; o aumento da satisfação e do bem estar dos usuários; o estímulo às políticas públicas de fomento a construções sustentáveis e ao valor ambiental; o uso racional e a redução da extração dos recursos naturais; a redução do consumo de água e energia; a implantação consciente e ordenada; a mitigação dos efeitos das mudanças climáticas; o uso de materiais e tecnologias de baixo impacto ambiental; e, a redução, o tratamento e o reuso dos resíduos da construção e da operação do estádio. (GHG Protocol, 2004)

Questões adicionais a serem conjecturadas conforme FIFA(2011) são as vias adequadas para os eixos de transporte e áreas de estacionamento; os serviços para os espectadores no local que devem incluir 
toaletes e instalações sanitárias; produtos promocionais; alimentos e bebidas; o conhecimento das construções adjacentes e do uso do solo para que não afetem a função do estádio durante o campeonato; o conhecimento dos direitos de comercialização local e implantação de medidas de segurança para a prevenção de riscos.

Sobre o transporte, a FIFA (2011) requer o aumento do uso do transporte público nos eventos que organiza. Idealmente, para que tal atitude ocorra por parte dos participantes recomenda que a localização perfeita seja um local em um grande centro urbano com bom acesso ao transporte público, ruas largas, rodovias e estacionamento que possam ser utilizados para outros fins quando não haja jogos. Isso também reduz a possibilidade de que grandes áreas de estacionamento sejam usadas por períodos inferiores a 100-200 horas por ano. Para os organizadores de eventos internacionais é mais interessante que haja hotéis e centros comerciais e pelo menos um aeroporto internacional nas proximidades do estádio/arena. Para melhor avaliar as exigências de transporte de potencial localização de estádio, as autoridades devem envolver engenheiros e planejadores de serviços de transporte, além de realizar uma detalhada avaliação do impacto dos transportes antes da escolha final do local. Conforme está descrito no documento o desenvolvimento da infraestrutura de transporte é dispendioso. Nesse, se sugere que a decisão final sobre a localização do estádio considere a proximidade da infraestrutura de transporte público aquático, terrestre e aeroviário.

A melhora no sistema de transporte coletivo deve ser o que mais beneficiará a comunidade local, principalmente o transporte rodoviário e ferroviário muito utilizado cotidianamente pela população. Contudo isto somente será garantido com obras estruturais e com a aquisição de equipamentos de mobilidade e acesso que permaneçam pós evento.

Para a FIFA (2011), os estádios devem ser localizados em um lugar suficientemente espaçoso para a circulação e para manter as atividades do público externo com segurança e para a manobra de veículos de serviço e operações. Enquanto é normal que os espectadores cheguem ao estádio espaçadamente durante um longo período de tempo para evitar filas desnecessárias nas catracas, a maioria tende a sair do estádio ao mesmo tempo, o que aumenta a necessidade de espaço. Como referência, a área considerada ideal para a realização do evento está entre 18 e 24 ha, o que depende da fase do campeonato a ser realizada no estádio.

Parece contraditório imaginar um centro urbano na atualidade com capacidade para realizar um megaevento, receber a quantidade de participantes que o evento compreende e considerar que tal espaço para o estádio/arena possa ter tal área disponível. Caberia uma resposta mais clara nesses documentos do que é um local "suficientemente espaçoso" e como seria possível reservar tal espaço para um evento que provavelmente seja realizado uma única edição na localidade ou demorará muitos anos para ser realizado novamente na mesma cidade sede.

O documento da FIFA (2011) também prevê o paisagismo do entorno do estádio. Segundo as informações contidas nele deve ser considerado um paisagismo abrangente. Neste é alegado que as áreas verdes presentes no local do estádio melhora a percepção e a realidade de que a instalação respeita o meio ambiente e sua vizinhança. O plantio de arbustos, árvores e jardins ao redor do projeto poderiam produzir um grande benefício visual para quem utiliza o estádio e para a comunidade local. O impacto sobre lençóis freáticos de rios e lagos próximos ao local do estádio e, consequentemente, a capacidade de drenagem do campo também deve ser considerado pelos comitês organizadores.

Há de se considerar até que ponto uma vegetação como meio de intervenção urbanística deve ser colocada no rol da garantia da sustentabilidade ecológica. Atenta-se que são recomendações requerimentos da entidade, e não obrigações ou regulamentos de obrigatoriedade para execução dos planejadores, comitê organizador local ou gestores públicos das cidades anfitriãs. Uma dimensão ambientalista deve primar pela preservação e a garantia de espécies locais. O paisagismo neste documento aparece mais como uma alegoria decorativa do espaço do entorno da instalação esportiva. Dentro do estádio, as recomendações são seguidas de modo mais categórico, enquanto no entorno caberá principalmente das decisões dos entes governamentais se a farão ou não, visto que a plataforma Leed caberá às obras do estádio para certificação.

A respeito das relações com a comunidade, no documento FIFA (2011) está descrito que é vital o contato prévio e a consulta junto aos representantes das comunidades locais, grupos ambientais e autoridades locais e nacionais do futebol durante a escolha do local e o projeto de um estádio. Com comunicação adequada, a expectativa de um novo estádio no ambiente deve ser uma experiência positiva, que para esta organizadora do megaevento esportivo, os benefícios locais de um novo estádio são consideráveis e incluem: acesso conveniente a esportes e eventos de entretenimento de qualidade; empregos durante a construção e na operação das instalações; novos visitantes, os quais aumentarão a viabilidade financeira 
da economia local, incluindo visitantes a lojas, restaurantes e hotéis. De acordo com o documento, frequentemente o estádio inclui instalações como ginásio, salas de preparo físico, piscina, creche, salas de atividades, salas de reuniões, lojas e outros centros culturais e sociais, as quais são primariamente utilizadas pelos habitantes da região. Em caso do campo ser de grama sintética, está que ele poderá ser disponibilizado para programas de recreação local. Sobre a promoção de eventos nos estádios é defendido que melhora significativamente a exposição e o perfil da comunidade sob a alegação que estes estádios aumentam a auto-estima da comunidade devido à natureza especial de sua estrutura e de seus eventos.

Segundo FIFA (2011), todos os fatores acima devem aumentar a qualidade de vida dos habitantes da área, assegurando que o estádio permaneça integrado ao cotidiano da comunidade e proporcione maior estabilidade financeira. E devido à natureza especial dos deles, frequentemente são objetos de rumores negativos e receios na mídia. Por esta razão é essencial que seja mantida uma comunicação direta com a comunidade local e com a imprensa durante o período de desenvolvimento e toda a vida operacional do estádio.

Conforme está descrito em FIFA (2011) a disponibilidade de espaço externo também permitirá futuras expansões ou novos desenvolvimentos, posto que muitos dos estádios famosos em todo o mundo estão localizados em áreas intensamente urbanizadas, rodeados por vias de tráfego, edifícios e canais nas imediações. Por estes fatores que são apresentados suas possibilidades de reforma e redesenvolvimento são limitadas pela sua área de localização, o que é indesejável. Grandes áreas reduzem a probabilidade de necessidade de futura mudança seja a curto ou longo prazo. E as áreas maiores também aumentam a possibilidade de oferta de áreas de estacionamento - uma exigência que provavelmente continuará no futuro próximo. Quanto mais suburbano e isolado for o local do transporte público, maiores são os requisitos de espaço de estacionamento. Nessa situação, é essencial a existência de acessos múltiplos e convenientes às principais vias e rodovias. Com uma boa análise, projeto e controles operacionais, a maioria desses problemas pode ser reduzida para satisfazer os moradores da região. Os exemplos que constam em FIFA (2011) incluem planos de tráfego e de gerenciamento de multidões nos dias de jogos, zonas de acesso restrito, abafadores de ruído e controles defletores de iluminação, construção do estádio abaixo do nível do solo para reduzir sua altura e a inclusão de atividade durante os períodos ociosos.

Vale um questionamento sobre o ressignificado desses espaços em que estão localizados os estádios que pós evento costumam se transformar em arenas multiuso e, ao invés de receber alguns eventos deverão ter a maior parte do tempo ocupado com várias tipologias de eventos de grande porte para justificar as intervenções no espaço físico e a demanda financeira de alto custo que realizar um evento de porte macro requer. (Campos et al, 2004)

Outro ponto divergente que se observou com esta pesquisa documental foi que, quando se coloca o desenvolvimento sustentável em pauta, é pensar em maiores áreas para estacionamento principalmente em centros já urbanizados. A sustentabilidade ecológica e a ambiental prima pelo uso de meios de transporte menos poluentes, valorização do uso de bicicletas, de caminhadas, do transporte coletivo em benefício da saúde da sociedade e do planeta. Não parece que "pensar" estacionamentos e aumentar a carga no espaço seja algo que defenda os pilares da sustentabilidade. O aumento do uso de veículos e da carga, visto que não se pode aumentar a capacidade de um local receber a carga é contrário à manutenção da vida no agora para garantia da qualidade de vida para as gerações futuras como conceituou Brundtland (1987). Sabem os defensores dos princípios do desenvolvimento sustentável que se deve levar em conta o repensar, readaptar, reciclar, reaproveitar. Pensar em sustentabilidade é readequar, ir e voltar em ideias que se uma hora parecem cabíveis devem ser reavaliadas a todo instante. Assim não parece cabível aumentar os impactos ambientais ou danos ecológicos, nem os sociais em uma localidade para receber um evento alienígena àquela comunidade sob a égide que estádios que depois ficam caracterizados como arenas e que aumentariam a auto-estima daquela comunidade devido à natureza especial de sua estrutura e eventos.

"Um dos motivos pelos quais as verbas de impostos municipais e estaduais são investidas no esporte profissional é a crença que este atua como catalisador para a construção da comunidade civil. Os megaeventos esportivos atendem funções similares em nível global. As cidades gastam quantias enormes de dinheiro para concorrer a eventos esportivos grandes e de alta visibilidade e recebê-los como maneira de promover a 'imagem' da cidade para o resto do mundo. A construção do estádio e da infraestrutura esportiva está ligada aos planos de regeneração urbana por meio da crença que os times e eventos dos esportes de elite estimulam a economia local e a geram empregos. No entanto, os acadêmicos que estudam o desenvolvimento urbano relativo ao esporte refutam a ideia que esse tipo de investimento cívico proporciona benefícios reais para a cidade como um todo. A evidência empírica revela que, embora alguns grupos de uma cidade possam lucrar, os outros são onerados." (Schimmel, 2013, p. 105-6). 


\section{Considerações finais}

Ao ler o marco histórico traçado para o conceito de sustentabilidade ser inserido nos megaeventos, podemos melhor compreender o viés escolhido sobre a valorização da questão ambiental impregnada de significados pela complexidade desse evento dentro de tudo que se faz necessário para sua realização. Embora não seja o caso em discussão, contudo depreende-se inclusive o discurso de legado que gestores de cidades candidatas carregam.

Tanto o Comitê Organizador Internacional que adicionou em seus ideais olímpicos o terceiro interesse e também na FIFA tem-se estabelecido um contundente nexo ambientalista. Fatores como o uso consciente da água e da energia, o repensar a produção e o descarte de rejeitos, as intervenções para garantia de acesso por meio de transporte adequado às necessidades dos participantes e da população autóctone, da ressignificação das instalações esportivas que são transformadas em arenas dos mais diversificados usos para espetáculos da era moderna viabilizando-as economicamente. Ficam registrados os Jogos Olímpicos de Sydney pela tentativa de um megaevento sustentável e o Programa Green Goal como paradigma para eventos futuros da FIFA.

Cada vez mais pesquisas cujo interesse deve levar em consideração a Declaração Ostersund do Turismo de Megaeventos é item relevante e inesgotável, visto que é crescente o mercado de eventos e têm sido realizados em toda a esfera terrestre. E principalmente esse segmento dos megaeventos que requer tantas condições para sua estruturação em uma localidade receptora, na qual sua organização ultrapassa os limites do coração do evento, a instalação esportiva. Vislumbrando que sejam conhecidas as consequências sociais e econômicas inclusive as de longo prazo, a autora deste estudo sugere que seja realizada uma pesquisa que aprofunde os estudos sobre os efeitos desses megaeventos esportivos na criação da imagem dos países, das regiões e da localidade anfitriã e os relacionados à atração de turistas pós evento; o desenvolvimento de estratégias para a realização dentro da estrutura geral da política de planejamento turístico local, regional e nacional e outras abordagens sobre os impactos turísticos. Análises em função dos impactos sociais, econômicos, ambientais, culturais e físicos devem ser conjecturadas não apenas para que haja um aperfeiçoamento na coordenação global da administração, mas as pesquisas dos megaeventos devem de antemão contribuir para a sociedade do núcleo receptor e comunidade autóctone do entorno do espaço de realização do evento propriamente dito em auxílio ao desenvolvimento social e econômico, que prezem pela sustentabilidade em ângulos maiores que a priorização do nexo ambientalista ou nexo ecológico.

O People é um dos tripés da sustentabilidade na visão empresarial, trata do social quando este menciona ser vital o contato prévio e a consulta junto aos representantes de comunidades que poderão ser afetadas pela realização do megaevento esportivo. Os grupos que deveriam ser consultados segundo esse tripé nesse caso são as comunidades locais, grupos ambientais e autoridades locais e nacionais do futebol durante a escolha do local e o projeto de um estádio. Com comunicação adequada e benefícios locais de: acesso conveniente a esportes e eventos de entretenimento de qualidade; empregos durante a construção e na operação das instalações; aumento do fluxo turístico, os quais aumentarão a viabilidade financeira local, programas de recreação e que a promoção de eventos melhora significativamente a exposição; a autoestima da comunidade por meio do aumento da sua qualidade de vida e bem estar. Espera-se que isto ocorra ao menos para as populações que vivem no entorno das instalações esportivas permanentes e que são construídas especificamente para os megaeventos, abrangendo o capital humano quer seja da empresa ou da sociedade. Assim sugere-se que um próximo estudo possa inserir a consulta aos autóctones da região receptora de um megaevento para avaliar se estes preceitos que são indicados pela entidade FIFA aos gestores e comitê organizador foram satisfatoriamente alcançados na percepção destes residentes do entorno da instalação esportiva nas sedes de megaeventos.

\section{Bibliografía}

Allen, Johnny; O’Toole, William; Mcdonnel, Ian; Harris, Robert. 2008. Organização e Gestão de eventos. Rio de Janeiro: Campus. Andranovich, Greg; Burbank, Mathew; Heaving, Charles.

2001. "Olympic cities; lessons learned from mega-events politics". Journal of Urban Affairs. 23 (2): 113-131. Bartholo, Roberto; Delamaro, Maurício e Badin, Luciana (Orgs.).

2005. Turismo e sustentabilidade no Estado do Rio de Janeiro. Rio de Janeiro: Garamond. 
Bonnenfant, R.

2001. "La modernization des Équipements et Installations Sportifs". AIRES: Association pour L'Information et la Recherche sur Équipements de Sport et de Loisir, Édition de la Lettre du Cadre Territorial.

Britto, Janaína; Fontes, Nena.

2002. Estratégia para eventos: uma ótica do marketing e do turismo. São Paulo: Aleph.

Brundtland, Gro Harlem.

1991. Relatório Brundtland 1987. Comissão Mundial sobre Meio Ambiente e Desenvolvimento: o nosso futuro comum. Rio de Janeiro: Fundação Getúlio Vargas.

Campos, Luiz Claudio de A. Menescal; Wyse, Nely; Araújo, Maria Luiza Motta da Silva.

2000. Eventos: oportunidade de novos negócios. Rio de Janeiro: SENAC Nacional.

Ciegis, R. Ramanauskiene, J. e Martinkus, B.

2009. "The concept of sustainable development and its use for sustainability scenarios". In Engeenering Economics. 20 (2): 28-37.

Dacosta, Lamartine Pereira (Org.)

2008. Brasil. Ministério do Esporte. "Legado de Megaeventos Esportivos". Conselhos Federal e Regionais de Educação Física. Brasília.

Del Río Rama, Maria de la Cruz; Álvarez García, José; Martins Ferreira, Ângela Maria

2016. Análise do efeito nas economias locais de megaeventos culturais e esportivos. Revista de Pesquisa em Ciências Contábeis e Administrativas (Journal of Research em Ciências da Contabilidade e Gestão) Vol. 1, No. 2, janeiro-junho 2016, 103-126. Disponível em: <http://ricca.umich.mx/index.php/ ricca/article/view/17/20> Acessado em 22.12.2017

Duarte, Rosália.

2002. "Pesquisa Qualitativa: Reflexões sobre o trabalho de campo". Cadernos de Pesquisa, 115: 139-154. Elkington, John.

1999. "Triple bottom-line reporting: Looking for balance". In: Australian CPA, 69(2), 18.

FIFA

2011. "Football's Footprint Legacy Report". Final report on the environment initiative of the FIFA Women's

World Cup 2011 Disponível em<http://www.fifa.com/mm/document/afsocial/environment/01/57/12/83/ fwwc2011green_goal_legacy_report_en.pdf> acessado em 24.04.2014

FIFA

2011. "Footbal Stadium: recomendation and requirements". Disponível em <http://www.fifa.com/> acessado em 02.04.2013. Fontes, Nádia; Zanin, Maria; Teixeira, Bernardo Arantes do Nascimento;

Yuba Andrea Naguissa; Shimbo, Ioshiaqui; Ino, Akemi; Leme, Patrícia Cristina Silva.

2008. "Eventos mais sustentáveis". São Paulo: Edufscar.

Freeman, Edward

2010. "A Stakeholder theory of the Modern Corporation". Disponível em <http://ufolio.uoregon.edu/

lcbleadership/files/2008/03/edward-freeman.pdf> acessado em 29.05.2010.

Gastaldo, Édison

2002. Pátria, Chuteiras e Propaganda: o brasileiro na publicidade da Copa do Mundo. São Paulo: Annablume.

Getz, Donald

1997. Event Management and Event tourism. New York: Cognizant Communication Corp.

GHG Protocol

2004. "A Corporate Accounting and Reporting Standard" Revised Edition. The Green House Gas

Protocol Disponível em <http://www.ghgprotocol.org/files/ghgp/public/ghg-protocol-revised.pdf >

Acesso: 20.07.2014

Morin, Edgar.

2011. Introdução ao pensamento complexo. Porto Alegre: Sulina, 2011.

Morin, Edgar.

2003. A cabeça bem-feita: repensar a reforma, reformar o pensamento. Rio de Janeiro: Bertrand Brasil, Irving, Marta de Azevedo

1998. "Turismo e ética: premissa e um novo paradigma" In: Coriolano, Luzia Neide M. T. (Org.). Turismo com ética. Fortaleza: Uece.

Leme, Ana Flávia Paes

2008. "Revisão East London para Legados de Jogos Olímpicos e Paraolímpicos" In: Da Costa (Org.) Legados de Megaeventos Esportivos. Rio de Janeiro. 
Martin, Vanessa

2003. Manual Prático de Eventos. São Paulo: Atlas.

Mascarenhas, Gilmar; Bienenstein, Glauco; Sánchez, Fernanda

2011. O Jogo continua: megaeventos esportivos e cidades. Rio de Janeiro: Uerj.

Mitchell, Ronald K.; Agle, Bradley R.; Wood, Donna J.

1997. "Toward a Theory of Stakeholder Identification and Salience: Defining the Principle of Who and MMA

What Really Counts” The Academy of Management Review, 22 (4).

2014. "Ministério do Meio Ambiente" <www.mma.gov.br> acessado em 18.11.2014

Nielsen, C.

2002. Turismo e Mídia: o papel da comunicação na atividade turística. São Paulo: Contexto.

Oliveira, José A. Puppim de.

2008. Empresas na sociedade: sustentabilidade e responsabilidade social. Rio de Janeiro: Elsevier.

OMT

1994. "Agenda 21 for the travel and tourism industry. Towards environmentally sustainable development".

Madrid. Disponível em <http://www2.unwto.org/ > acessado em 13.02.2014

OMT - Organização Mundial do Turismo

1996. "Tourist Safety and Security: Practical Measures for Destinations: Measures for Destinations".

Madrid. Disponível em <http://www2.unwto.org/ > acessado em 13.02.2014

Owen, J.

2005. "Estimating the cost and benefit of hosting Olympic Games: what can Beijing expect from its 2008 Games?" The Industrial Geographer, USA, 3 (1): 1-18.

Preuss, H.

2000. "The Economic Impact of Visitors at Major Multi-sport Events". European Sport Management Quarterly.

Preuss, H.

2007. "The conceptualisation and measurement of mega sport event legacies". Journal of Sport and Tourism.

Proni, Marcelo Weishaupt; Faustino, Raphael Brito e da Silva Leonardo Oliveira.

2014. Impactos econômicos de megaeventos esportivos. Belo Horizonte: Casa da Educação Física.

Ribeiro, Fernando Telles.

2008. "Legado de Megaeventos Esportivos Sustentáveis: a importância das instalações esportivas" In:

Dacosta, Lamartine Pereira (Org.). Legado de Megaeventos Esportivos. Brasil. Ministério do Esporte

e Confef. Brasília.

Ritchie J. R. B., Yangzhou J.

1987. The Role \& Impact of Mega-events and Attractions on National and Regional Tourism Development:

A Conceptual and Methodological Overview. In: Proceedings of the 37th Annual Congress of the

International Association of Scientific Experts in Tourism (AIEST) (p. 17-58). Calgary.

Schimmel, K. S.

2013. Os grandes eventos esportivos: desafios e perspectivas. Belo Horizonte: Unicamp.

Selltiz, Claire, Jahoda, Marie, Deutsch, Morton e Cook, Stuart.

1967. Métodos de Pesquisa nas Relações Sociais. São Paulo: Herder - EDUSP.

Senado Federal

2012. "Da Rio-92, em 1992, à Conferência das Nações Unidas sobre Desenvolvimento Sustentável

(Rio+20), no Rio de Janeiro, em 2012: negociações sobre o meio ambiente do planeta" Disponível

em < http://www.senado.gov.br/NOTICIAS/JORNAL/EMDISCUSSAO/rio20/a-rio20.aspx> acessado em 17.11.2014

Silberberg, Carolina Piccin e Mac Dowell, Daniela

2010. "Gestão Ambiental e Responsabilidade Social em Eventos" In: Philippi Jr., Arlindo; Ruschmann,

Dóris Van de Meenne. Gestão Ambiental e Sustentabilidade no Turismo. Barueri: Manole.

Silva, E.G.B

2015. Reflexões sobre a sustentabilidade e as transformações causadas pelo megaevento esportivo Copa do Mundo 2014 no Estádio do Maracanã/RJ e seu entorno. Dissertação. Brasília. Universidade de Brasília.

Sousa, Almir Ferreira de; Almeida, Ricardo José

2006. O Valor da Empresa e a influência dos Stakeholders. São Paulo: Saraiva.

Standeven, J. De Knop, P.

1999. Sport tourism. Champaign. IL: Human Kinetics. 
Swarbrooke, John.

2000. Turismo sustentável: gestão e marketing. São Paulo: Aleph.

Trigueiro, André (Coord.).

2003. Meio Ambiente no século 21. Rio de Janeiro: Sextante.

UNEP

2011. "Towards a Green Economy: Pathways to Sustainable Development and Poverty Erradication".

Disponível em <www.unep.org/greeneconomy> acessado em 19.11.2014.

US Green Building Council (2014). US Green Building Adoption Index. Disponível em <http://www.

usgbc.org/resources/leed-v4-building-design-and-construction-current-version >. Acesso: 13.11.2014 Vigneau, François.

1998. Les Espaces du Sport. Paris: PUF. 